\title{
Investigation of monthly and seasonal changes of methane gas with respect to climate change using satellite data
}

\author{
Safieh Javadinejad ${ }^{1} \cdot$ Saied Eslamian $^{2} \cdot$ Kaveh Ostad-Ali-Askari $^{3}$ D
}

Received: 14 January 2019 / Accepted: 3 October 2019 / Published online: 15 October 2019

(c) The Author(s) 2019

\begin{abstract}
Climate change and global warming are the biggest challenges in the current century. Methane gas is one of the most important greenhouse gases which can contribute to creating warming weather (about 19\%). In this research, satellite data from GOSAT and MODIS and also climatic data of precipitation, temperature and humidity are used to analyze monthly and seasonal methane changes in 2012 to 2018 in North America. The results show that the methane gas has increased during this period and it increases from 1789 to $1824 \mathrm{ppb}$. The gas has monthly fluctuation and in October and September has the maximum concentration and in March and April has the minimum value. The relationship between the methane gas and temperature and LST is positive, and the relationship between the methane gas and NDVI, precipitation and humidity is negative. This verifies that the increase in methane concentration has significant relationship with low vegetation cover and high temperature. Therefore, conservation of vegetation cover can help to reduce the methane concentration.
\end{abstract}

Keywords Methane concentration $\cdot$ Climate change $\cdot$ Global warming $\cdot$ Satellite data $\cdot$ NDVI $\cdot$ LST

\section{List of abbreviations}

LST

NDVI

GOSAT

MODIS

Land surface temperature

$\begin{array}{ll} & \text { Spectroradiometer } \\ \text { EPA } & \text { Environmental Protection Agency }\end{array}$

NIES National Environmental Studies

Association

TANSO-FTS Greenhouse gas observation sensor

Kaveh Ostad-Ali-Askari

kaveh.oaa2000@gmail.com

Safieh Javadinejad

SXJ228@bham.ac.uk

Saied Eslamian

pro.eslamian@gmail.com

1 University of Birmingham, Edgbaston St., B152TT Birmingham, UK

2 Department of Water Engineering, College of Agriculture, Isfahan University of Technology, Isfahan, Iran

3 Department of Civil Engineering, Najafabad Branch, Islamic Azad University, Najafabad, Iran

\section{Introduction}

Climate change, especially global warming, has attracted attention due to rising greenhouse gas emissions in the atmosphere. $\mathrm{CO}_{2}$ and other greenhouse gases, including $\mathrm{CH}_{4}, \mathrm{~N}_{2} \mathrm{O}$, HFCs, PFCs and SF6, are the ones that their release is under the control of the Kyoto Protocol (Iwata and Okada 2014). Methane gas alone accounts for more than $18 \%$ of the heat generated from greenhouse gas emissions. Changing the methane rate from 700 to 1808 ppb between 1850 and 2010 has shown an increase of $158 \%$ since the industrialization period (Heede 2014). The methane cycle has seasonal variations, which depend on the seasonality of the production resources (wetlands, rice fields and burning biomass) and the outflow from the atmospheric reaction of this gas (Saunois et al. 2016). Methane release sources are divided into three categories: thermogeneic, biogenetic and pyrogenic. Biogenic involves the production of microbial methane in anaerobic environments such as natural wetlands and rice fields, limited fresh oxygen reservoirs, including dams, digestive system of ruminant, termite and leachate sewage disposal sites and animal fertilizers (Wu et al. 2018). Thermogenic sources include explosions, fossil fuels from the ground and natural volcanoes, and pyrogenic sources include incomplete combustion of fossil fuels. There are various ways to measure greenhouse gases, including the 
use of ground bases in tall towers, ships, airplanes, airships and satellites (Schaefer et al. 2016). In the context of satellite monitoring of greenhouse gases, AIRS, SCIAMACHY, GOSAT and OCO-2's sensors can be mentioned (Alexe et al. 2015). Currently, GOSAT is the only satellite that measures greenhouse gas mechanics and has a precision measurement of less than $1 \%$ (Kuze et al. 2016). Considering the new satellite monitoring of greenhouse gases, many studies have not been carried out in this area. Only a study in this area was conducted by Turner et al. 2015. They examined the use of MODIS satellite data to study the monthly and seasonal changes in greenhouse gas emissions of carbon dioxide. Given the widespread concern in the international community about climate change and according to reports by the Institute for International Natural Resources on the location of the leading greenhouse gas emissions in the Portal 2015, as well as the lack of ground bases, measurement of greenhouse gases in this area in the present study uses satellite data of GOSAT to investigate the monthly and seasonal changes in methane gas in this area (McKain et al. 2015). Considering the necessity of implementing the Environmental Council's regulations on the design and deployment of a low-carbon economy system, the purpose of this study is to extract the satellite's monitoring of methane gas and analyze its changes in this region in terms of time and the reasons that it can be understanding the potential sources of carbon emissions and releases, planning for macroeconomic policies and environmental measures to help assess the carbon cycle equilibrium of drought ecosystems.

\section{Materials and methods}

\section{Study area}

North America is bounded to the north via the Arctic Ocean, to the east through the Atlantic Ocean, to the west and south through the Pacific Ocean and to the southeast through South America and the Caribbean Sea (King 2015).

The area of North America is about 24,709,000 km $(9,540,000$ square miles). North America is the third biggest continent through area, after Asia and Africa, and the fourth through population following Asia, Africa and Europe. The population is assessed about 580 million people in 2018 .

North America has different kinds of climate, from the dry, mild cold of the Arctic to the humid of the tropics. The central of Greenland always has subzero temperatures. The North American tundra, the enormous treeless plain of the far north, temperature can increase above freezing for just a short period each summer. In the far south, there are some regions which always have hot and rainy weather.

The residue of North America is cold in the winter and warm in the summer, with slight precipitation. Some regions have slight winters and long hot summers, and other districts have severe winters and slight summers. North America expands to within $10^{\circ}$ of latitude of both the equator and the North Pole and embraces every climatic zone, from tropical rain forest and savanna on the lowlands of Central America to regions of enduring ice cap in central Greenland (Doubler et al. 2015).

North America includes the USA and Canada as two of the biggest global emitters of the greenhouse gases, especially methane and $\mathrm{CO}_{2}$, that can provide a warming climate. All ten of the "hotspot" classifications are found in this district, including alterations like polar warming in Alaska, coral reef bleaching in Florida, animal range shifts in California, glaciers melting in Montana and marsh loss in the Chesapeake Bay.

Environmental Protection Agency (EPA) inventory data represented that emissions from oil and gas and from livestock each estimated for about a third of the methane made by the North America, while landfill waste was calculated for $21-22 \%$ and coal was estimated for $10-13 \%$ of methane emissions (Sweeney et al. 2015).

North America methane emissions have enlarged through more than $30 \%$ in the past decade, making the area participate to the global rise in emissions. It seems the growth is largely due to supplies in the central area which is the only region in the nation to show statistically significant growths in methane production. Recent increases in oil and gas production as well as shale gas production can possibly estimate for this change; however, other supplies could be engaged as well.

\section{Data used in this study}

\section{Satellite level 2 data of GOSAT for the extraction of methane}

The satellite for estimating greenhouse was launched in 2009 on the island of Tangashima in Japan. GOSAT is a joint project of the Japan Space Exploration Agency, the Ministry of the Environment, the National Environmental Studies Association (NIES), with investment of 20 billion yen. The satellite is at a height of $166 \mathrm{~km}$ above the ground; each time it completes the rotation in about $100 \mathrm{~min}$, with a rotational time of $12 \mathrm{~min}$ and $48 \mathrm{~s}$. The primary objective of the GOSAT project is to accurately estimate the sources of emissions and greenhouse gas emissions in subcontinental scale to help environmental managers assess the carbon cycle equilibrium of terrestrial ecosystems. The satellite is the world's first satellite designed for measurements of carbon dioxide and methane oxide emissions from the SWIR band and global coverage every 3 days. The satellite is also tracked with a deviation of 98 degrees and has a spatial resolution of two tenths, and its spatial resolution is a circle of 
ten and a half $\mathrm{km}$. The satellite is equipped with TANSOFTS and TANSO-CAI sensors to measure greenhouse gases. The carbon dioxide and methane molecules in the atmosphere absorb rays of particular wavelengths and measure how much carbon dioxide and methane are found in pillars from the ground up to the top. The columns are taken at 5 -point latitude, at a radius of ten and a half $\mathrm{km}$, with an approximate distance of $100 \mathrm{~km}$ between these columns. Due to the fact that the time of the return of the satellite is every 3 days, there are many observations that cover the entire world, but because of the limitations of the cloudless conditions, only $10 \%$ of the observations made by TANSOFTS can be used to recover carbon dioxide and methane used. Satellite data of GOSAT have different levels, so that the data from the TANSO-FTS and TANSO-CAI sensors are level 1 data. These data are not validated and require validation. NIES is responsible for validating and developing algorithms for recovering average carbon dioxide and methane columns from level 1 data, and after validation by ground or airborne databases, surface-level data are generated. The accuracy of the evaluation of the frequency of retrieved columns for GOSAT is less than $1 \%$ in most cases.

\section{MODIS satellite products for monitoring vegetation cover and surface temperature}

MODIS sensor is an important tool installed on Terra and Aqua and is the most reliable data source on a continental scale. MODIS has 36 band spectra that collect data in a range of 14 to $14 \mathrm{~km}$ in range, and can view the whole surface of the earth for 1 to 2 days. One of the strengths of the MODIS is the global coverage of high-resolution separation and accurate calibration in visible near-infrared bands and infrared heat. More than 10 types of information can be extracted from MODIS. In the present study, MOD13Q1 and MOD11C3 products are used which represent the normalized plant differences (NDVI) and ground temperature (LST). After downloading the data from the site, due to the wide area of the study area and its location in different blocks, the data in the software ArcGIS 10.3 and using the mosaic method were put together, and in the end, the pixel size of the data was uniformly matched using the bilinear method.

\section{Meteorology data}

The meteorological parameters used in this study were the average monthly temperature, the average monthly relative humidity and the average monthly precipitation received by the meteorological organization. It is worth noting that these data were obtained after averaging of daily data. In this study, synoptic stations are located at less than $50 \mathrm{~km}$ from methane columns. In the present study, while there were
290 synoptic stations, only 62 of the stations that escaped less than $50 \mathrm{~km}$ from methane metering columns were used.

\section{Statistical analysis}

Statistical analysis and correlation coefficient between methane columns, meteorological parameters (temperature, humidity and rainfall) and LST and NDVI indicators from MODIS satellite in SPSS software were investigated. In order to examine the difference between the methane gas content of the study area in 2009 and 2015, one-way ANOVA was used and Duncan's test was used to determine the difference between the groups.

\section{Results}

\section{Descriptive statistics of the studied variables}

Table 1 describes the parameters of the methane variable and meteorological variables of temperature and humidity including mean, minimum, maximum, standard deviation and coefficient of variation.

\section{Methane change trends from 2012 to 2018}

Figure 1 shows the methane change from 2012 to 2018 using satellite data. Based on this chart, methane gas has had a steady increase over this period, with methane levels rising from 1785 to 1823 , indicating an increase of 35 this time in this region. Despite the fact that the region has joined the Kyoto Protocol in recent years and has announced the reduction in greenhouse gases in various sectors of energy, oil and gas and agriculture, natural resources and forestry, the continued increase in greenhouse gas emissions by using satellite data is visible in this area. The results of ANOVA test showed a significant difference between methane gas at 95\% level in all years (Tables 2, 3, 4).

Table 1 Statistical analysis of variables

\begin{tabular}{llll}
\hline & Methane $(\mathrm{ppb})$ & $\begin{array}{l}\text { Average tem- } \\
\text { perature }\left({ }^{\circ} \mathrm{C}\right)\end{array}$ & $\begin{array}{l}\text { Average } \\
\text { humidity } \\
(\%)\end{array}$ \\
\hline Min & 26 & -27 & 0 \\
Max & 1883 & 53 & 100 \\
Average & 1814 & 18 & 48 \\
Standard deviation & 21 & 913 & 27 \\
CV & 1.5 & 0.7 & 0.56 \\
\hline & & & \\
& & &
\end{tabular}




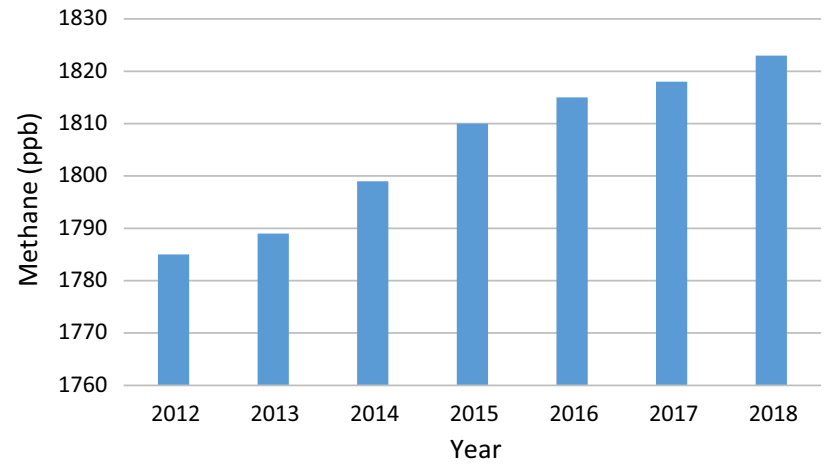

Fig. 1 Methane change trends from 2012 to 2018

Table 2 Correlation between climatic parameters and methane in 2018

\begin{tabular}{lccl}
\hline & Humidity & Precipitation & Temperature \\
\hline$R$ & -0.48 & -0.6 & 0.49 \\
$R^{2}$ & 0.23 & 0.26 & 0.24 \\
$P$ value & 0.14 & 0.12 & 0.14 \\
\hline
\end{tabular}

Table 3 Correlation between NDVI and methane in different months in 2018

\begin{tabular}{lcccc}
\hline & NDVI in winter & NDVI in autumn & NDVI in summer & NDVI in spring \\
\hline$R$ & -0.33 & -0.19 & -0.14 & -0.53 \\
$R^{2}$ & 0.11 & 0.035 & 0.020 & 0.28 \\
$P$ value & 0.04 & 0.207 & 0.37 & 0.008 \\
\hline
\end{tabular}

Table 4 Correlation between LST and methane in different months in 2018

\begin{tabular}{lllll}
\hline & $\begin{array}{l}\text { LST in } \\
\text { winter }\end{array}$ & $\begin{array}{l}\text { LST in } \\
\text { autumn }\end{array}$ & $\begin{array}{l}\text { LST in sum- } \\
\text { mer }\end{array}$ & LST in spring \\
\hline$R$ & 0.64 & 0.46 & 0.23 & 0.61 \\
$R^{2}$ & 0.41 & 0.21 & 0.050 & 0.37 \\
$P$ value & 0.00 & 0.001 & 0.15 & 0.003 \\
\hline
\end{tabular}

\section{Monthly change in methane from 2012 to 2018}

In this research, satellite data are used to verify the monthly fluctuations of methane gas. The survey reveals a monthly change from 2012 to 2018 in the region. Figure 2 shows the results. According to the results, the maximum concentration of this gas was observed in October and September and at least in most of the surveyed years in March.

Temperature is one of the effective factors in methane emissions. According to Fig. 3, with rising temperatures in the spring and summer, an increasing trend of methane gas is observed in these seasons. It should be noted that spatial

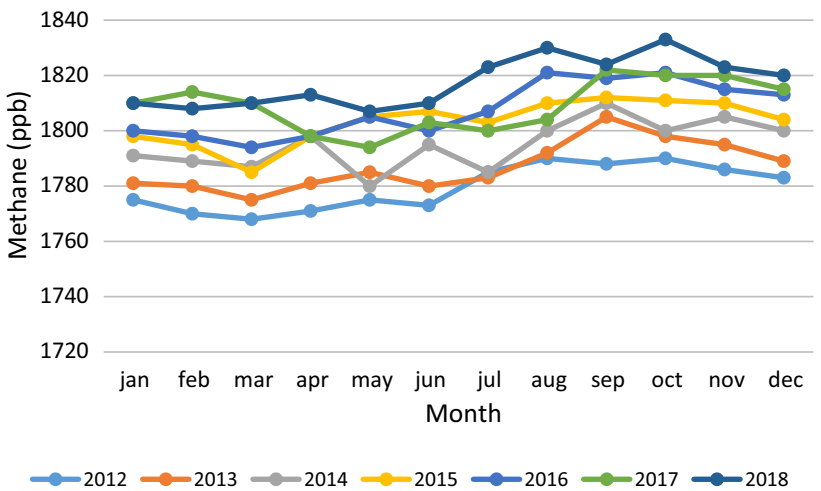

Fig. 2 Monthly change in methane from 2012 to 2018

free radicals of $\mathrm{OH}$ in dry air. As shown in Fig. 5, methane gas has a negative correlation with the rainfall variable in 2018, as the amount of methane concentration in the studied area decreases with increasing rainfall.

Figures $6,7,8,9,10,11,12$ and 13 show the relationship between methane gas and LST and NDVI indicators distribution of natural and human resources of methane emissions such as wetlands, rice fields, landfills and livestock breeding is one of the factors influencing the release of this gas in different months of the year.

\section{The relationship between methane and meteorological parameters and LST and NDVI}

Correlation coefficient was investigated to verify the relationship between methane gas and weather parameters including temperature, humidity rainfall, LST and NDVI in 2018. For the association of methane with methane parameters, the annual relationship and, for the association of LST and NDVI variables with this gas, the seasonal connection are considered. Figures 3, 4, 5, 6, 7 and 8 show the results.

As shown in Fig. 3, the results of the correlation between methane gas and the average monthly temperature of 2018 are positive, so that the concentration of methane gas increased with temperature rise in 2018.

According to Fig. 4, methane gas has a negative correlation with the humidity variable, so that in 2018, the concentration of methane gas decreased with increasing monthly relative humidity. The reason for this correlation is related to 


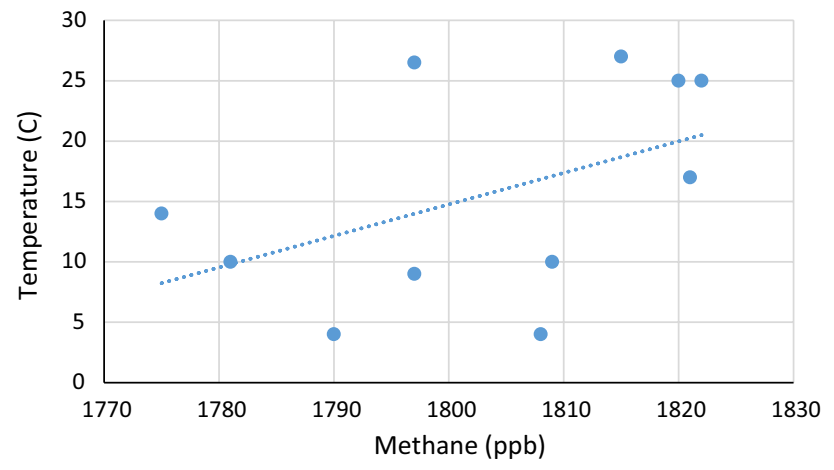

Fig. 3 Relationship between monthly methane and temperature in 2018

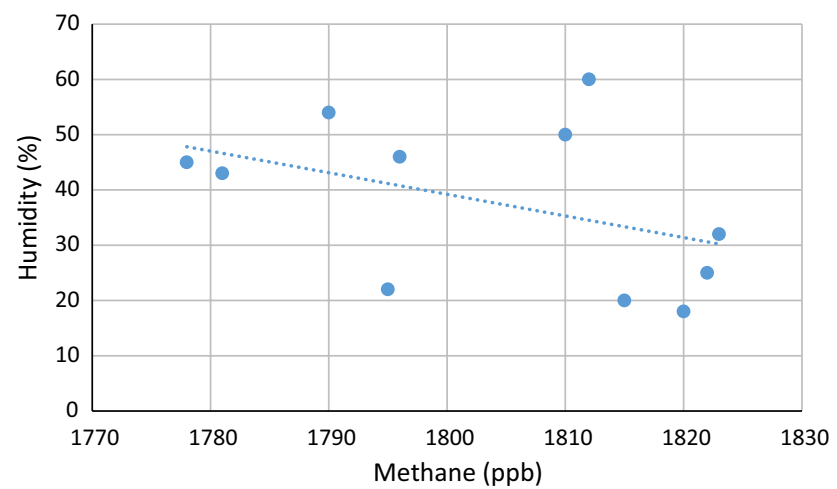

Fig. 4 Relationship between monthly methane and humidity in 2018

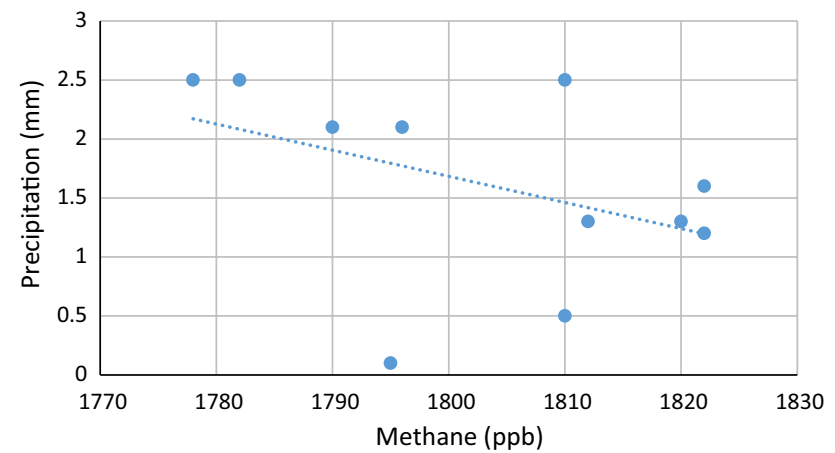

Fig. 5 Relationship between monthly methane and precipitation in 2018

in different seasons of 2018. In all seasons, the relationship between methane gas and the NDVI index is negative and the relationship between this gas and the LST index is positive. For spring and autumn, NDVI and methane connections are meaningful, and for LST, with the exception of summer, other seasons have meaningful connections. As the temperature increases and the NDVI decreases, in all seasons, the concentration of methane gas has increased.

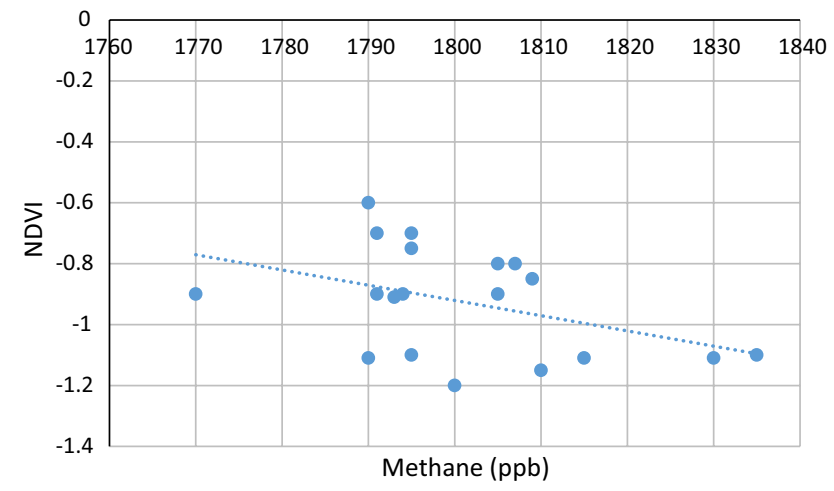

Fig. 6 Relationship between methane and NDVI in spring

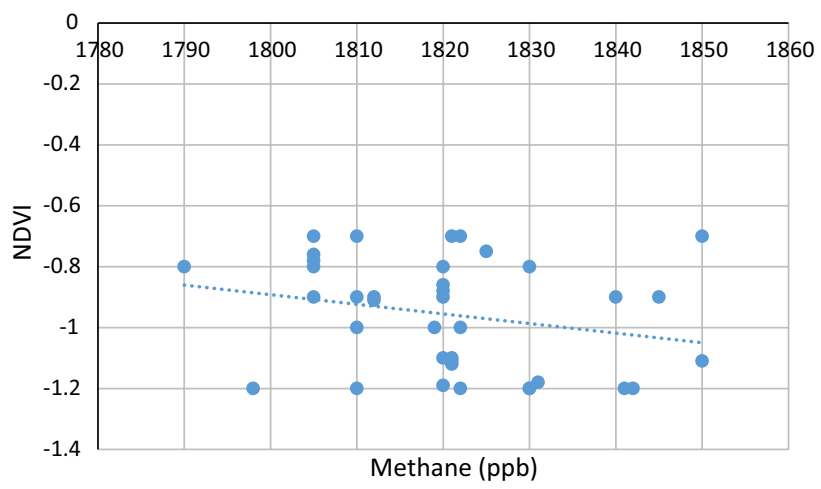

Fig. 7 Relationship between methane and NDVI in summer

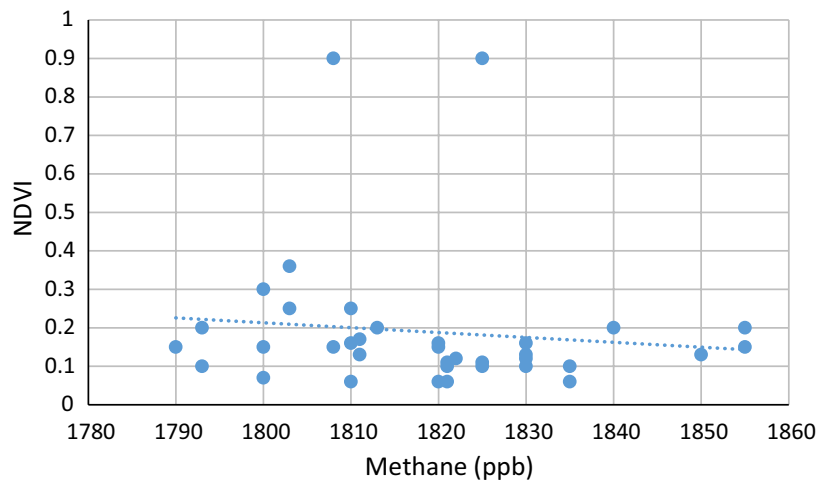

Fig. 8 Relationship between methane and NDVI in autumn

The correlation coefficients between methane gas and NDVI index in spring, summer, autumn and winter are $-0.53,-0.14,-0.19$ and -0.34 , respectively, and it shows that in the summer and autumn seasons, there is no relation between methane and methane gas. The correlation coefficient between this gas and the LST index of the seasons of spring, autumn and winter, respectively, is 0.7 , $0.23,0.46$ and 0.64 . 


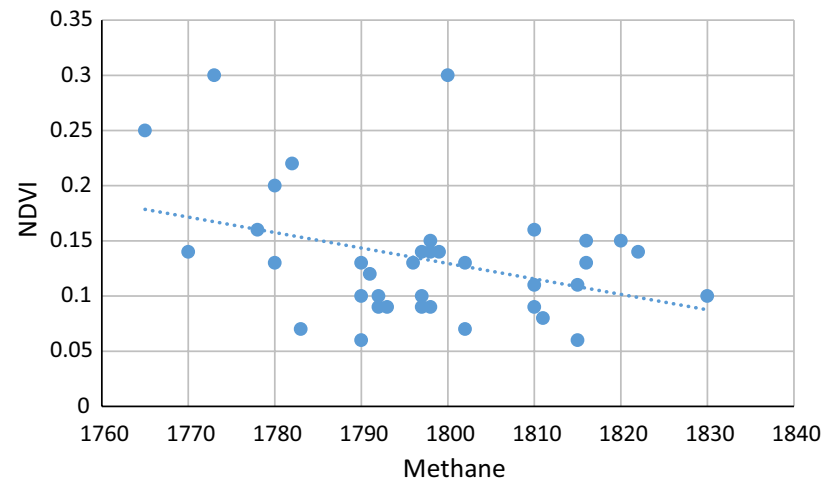

Fig. 9 Relationship between methane and NDVI in winter

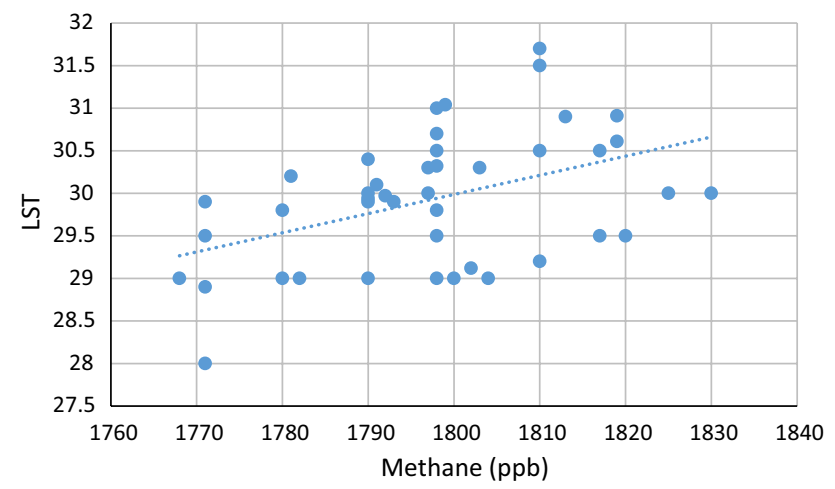

Fig. 10 Relationship between methane and LST in spring

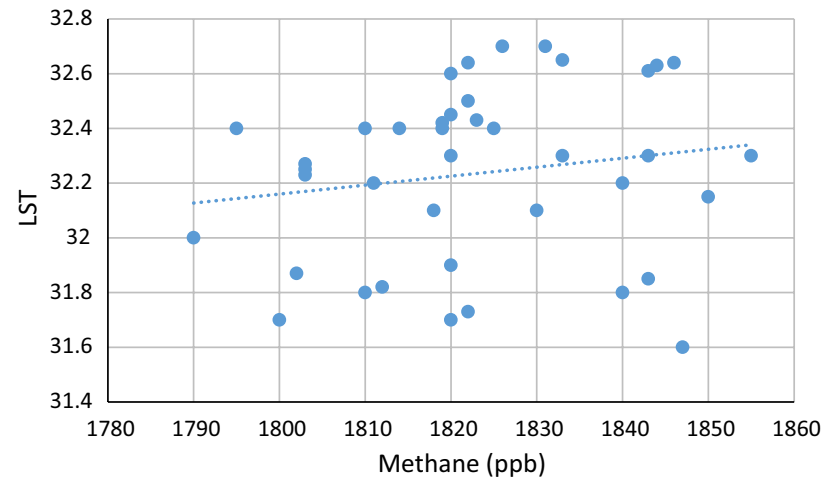

Fig. 11 Relationship between methane and LST in summer

\section{Discussion}

According to the results, methane gas has had a steady change from 2012 to 2018 so that the gas volume rises from 1789 to $1824 \mathrm{ppb}$, indicating an increase of $36 \mathrm{ppb}$ in the gas in the region. In this regard, Luo et al. (2015) explored the annual changes in carbon dioxide and

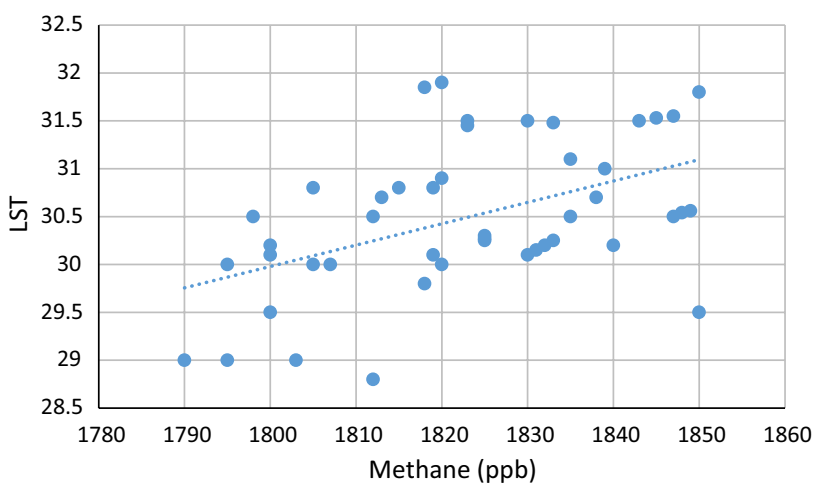

Fig. 12 Relationship between methane and LST in autumn

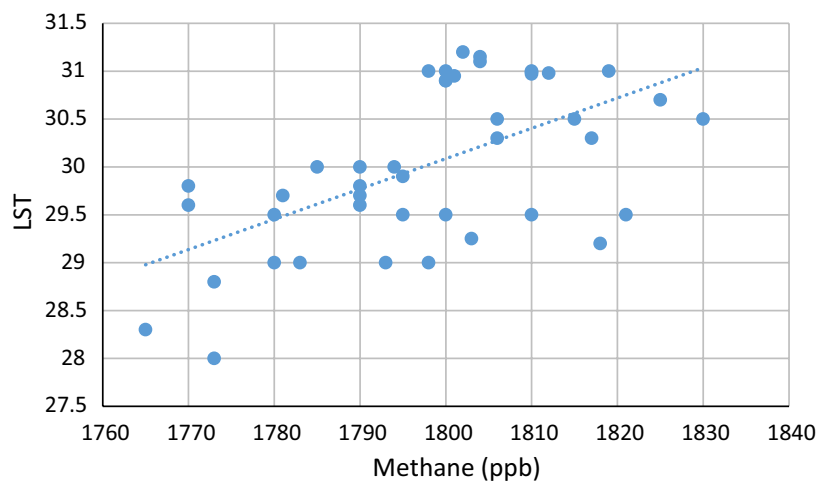

Fig. 13 Relationship between methane and LST in winter

methane gas in China and Mongolia using satellite. They saw an increasing trend in the changes in these two gases in their study area. In another study, Kumar et al. (2016) used the satellite and ground base of NOAA to study the trend of carbon dioxide change in India from 2003 to 2011. In their study, they saw an increasing amount of carbon dioxide, but did not see significant growth in methane in the study area. Thompson et al. (2015) reviewed the annual methane change from 2009 to 2013 in East Asia. In their research, they observed an increase in this gas in the studied area at a rate of 6 over the 5 -year period. Methane annual changes from 2007 to 2013 were also reviewed in a study by the Japan Meteorological Agency (Tsuboi et al. 2016). During this period, the average annual methane 6 was measured. The research results of the aforementioned studies confirm the increasing trend of methane in most parts of the world in recent years.

According to the results of this study, methane gas has seasonal fluctuations from 2009 to 2015 , so that the maximum concentration of this gas was observed in October and September and at least in most of the years under review in March. 
In similar studies, Dangal et al. (2017) reported a low concentration of methane in China and Mongolia in May and it peaked in September. They said that the rise in methane from May to September was due to rising temperatures during this period.

Akimoto et al. (2015) in the study of methane changes in East Asia witnessed seasonal changes in methane in their study area, which peaked in August and at least observed in February and March. Ganesan et al. (2017) measured India's minimum methane concentration in winter and its peak concentration in August and July. Chandra et al. (2017) in a study in the eastern region of India said that the reason for the increase in methane in summer is due to increased microbial activity in these areas. They came to the conclusion that since June, the average atmospheric methane concentration has increased, reaching its peak in August and September. In another study, Tian et al. (2015) linked seasonal changes to methane with rice cultivation, wetlands and burning biomass. The results of methane gas fluctuations in this study are consistent with the results of this study.

\section{Conclusion}

The present study shows that in all seasons the relationship between methane gas and NDVI index is negative and the relationship between this gas and the LST index is positive. As the temperature increases and the NDVI decreases, in all seasons, the concentration of methane gas has increased. It is worth noting, however, that all the expressed relationships do not have a high correlation with the methane variable. This is seen in similar studies in other countries. Finstad et al. (2016) reported that the relationship between methane and NDVI is negative and the regression coefficient of this gas with NDVI is 0.5. Kim et al. (2015) explored the spatial distribution of methane in East Asia and expressed concern about environmental parameters associated with greenhouse gases and understood that NDVI has a negative and significant relationship with methane. So if NDVI increases, then $\mathrm{CH} 4$ will decrease in the study area. They reported that the regression coefficient of this variable with NDVI is 0.7. They expressed the most important cause of methane reduction by oxidation of methane by free radical hydroxyl. The most important source of methane in the troposphere is its oxidation by free radicals of hydroxyl so that more than $90 \%$ of the atmospheric methane is released by these free radicals from the atmosphere. In the atmosphere, ozone molecules decay energy from the rays of the sun into $\mathrm{O}_{2}$ molecules and $\mathrm{O}$ atom and the result of the reaction of $\mathrm{O}$ atom with steam is the production of free radicals of hydroxyl $(\mathrm{OH})$. In areas where the temperature is high and the humidity is low, the atmosphere is reduced, and subsequently, the OH decreases. Sweeney et al. (2016) stated that methane emissions are sensitive to temperature so that a $10^{\circ}$ increase in temperature at the temperature range doubles the methane concentration. Based on the results of this study, which shows the relationship between methane gas content and LST temperature variables, and the negative relationship of this gas with NDVI variables, rainfall and humidity, in areas with high humidity and rainfall and low vegetation and regions with high temperature and high temperatures, the maximum concentration of methane gas is observed. Therefore, preserving natural ecosystems, especially plant coverings in arid and semiarid regions, can play an important role in regulating methane gas. In the end, it is suggested that, in order to understand the potential sources and outcomes of methane gas, the distribution of this gas on a national scale using satellite data is proposed.

Acknowledgements We thank Esfahan Regional Water Authority for funding this study to collect necessary data easily and help the authors to collect the necessary data without payment, Mohammad Abdollahi and Hamid Zakeri for their helpful contributions to collect the data and all other sources of funding for the research collected from authors. We thank ForoughJafary who provided professional services for checking the grammar of this paper.

Authors' contributions SJ designed this research, wrote this paper, collected the necessary data and did analysis of the data. SE participated in drafting the manuscript, contributed to the collection of data and interpretation of data and edited the format of the paper under the manuscript style. KOAA participated in the data collection and data analysis.

Funding We thank Esfahan Regional Agricultural Authority and Esfahan Regional Water Authority for funding this study to collect necessary data easily and help the authors to collect the necessary data without payment, Mohammad Abdollahi and Hamid Zakeri for their helpful contributions to collect the data and all other sources of funding for the research collected from authors.

\section{Compliance with ethical standards}

Conflicts of interest All authors have declared that they have no conflicts of interest.

Ethics approval and consent to participate Not applicable.

Consent for publication Not applicable.

Open Access This article is distributed under the terms of the Creative Commons Attribution 4.0 International License (http://creativeco mmons.org/licenses/by/4.0/), which permits unrestricted use, distribution, and reproduction in any medium, provided you give appropriate credit to the original author(s) and the source, provide a link to the Creative Commons license, and indicate if changes were made. 


\section{References}

Akimoto H, Kurokawa JI, Sudo K, Nagashima T, Takemura T, Klimont Z, Amann M, Suzuki K (2015) SLCP co-control approach in East Asia: tropospheric ozone reduction strategy by simultaneous reduction of NOx/NMVOC and methane. Atmos Environ 122:588-595

Alexe M, Bergamaschi P, Segers A, Detmers R, Butz A, Hasekamp O, Guerlet S, Parker R, Boesch H, Frankenberg C, Scheepmaker RA (2015) Inverse modelling of $\mathrm{CH} 4$ emissions for 2010-2011 using different satellite retrieval products from GOSAT and SCIAMACHY. Atmos Chem Phys 15(1):113-133

Chandra N, Hayashida S, Saeki T, Patra PK (2017) What controls the seasonal cycle of columnar methane observed by GOSAT over different regions in India? Atmos Chem Phys 17(20):12633-12643

Dangal SR, Tian H, Zhang B, Pan S, Lu C, Yang J (2017) Methane emission from global livestock sector during 1890-2014: magnitude, trends and spatiotemporal patterns. Glob Change Biol 23(10):4147-4161

Doubler DL, Winkler JA, Bian X, Walters CK, Zhong S (2015) An NARR-derived climatology of southerly and northerly low-level jets over North America and coastal environs. J Appl Meteorol Climatol 54(7):1596-1619

Finstad AG, Andersen T, Larsen S, Tominaga K, Blumentrath S, De Wit HA, Tømmervik H, Hessen DO (2016) From greening to browning: catchment vegetation development and reduced S-deposition promote organic carbon load on decadal time scales in Nordic lakes. Sci Rep 6:31944

Ganesan AL, Rigby M, Lunt MF, Parker RJ, Boesch H, Goulding N, Umezawa T, Zahn A, Chatterjee A, Prinn RG, Tiwari YK (2017) Atmospheric observations show accurate reporting and little growth in India's methane emissions. Nat Commun 8(1):836

Heede R (2014) Tracing anthropogenic carbon dioxide and methane emissions to fossil fuel and cement producers, 1854-2010. Clim Change 122(1-2):229-241

Iwata H, Okada K (2014) Greenhouse gas emissions and the role of the Kyoto Protocol. Environ Econ Policy Stud 16(4):325-342

Kim HS, Chung YS, Tans PP, Dlugokencky EJ (2015) Decadal trends of atmospheric methane in East Asia from 1991 to 2013. Air Qual Atmos Health 8(3):293-298

King PB (2015) Evolution of North America. Princeton University Press, Princeton

Kumar KR, Valsala V, Tiwari YK, Revadekar JV, Pillai P, Chakraborty $\mathrm{S}$, Murtugudde R (2016) Intra-seasonal variability of atmospheric $\mathrm{CO}_{2}$ concentrations over India during summer monsoons. Atmos Environ 142:229-237

Kuze A, Suto H, Shiomi K, Kawakami S, Tanaka M, Ueda Y, Deguchi A, Yoshida J, Yamamoto Y, Kataoka F, Taylor TE (2016) Update on GOSAT TANSO-FTS performance, operations, and data products after more than 6 years in space. Atmos Meas Tech 9(6):2445-2461

Luo X, Wang S, Wang Z, Jing Z, Lv M, Zhai Z, Han T (2015) Adsorption of methane, carbon dioxide and their binary mixtures on Jurassic shale from the Qaidam Basin in China. Int J Coal Geol 150:210-223
McKain K, Down A, Raciti SM, Budney J, Hutyra LR, Floerchinger C, Herndon SC, Nehrkorn T, Zahniser MS, Jackson RB, Phillips $\mathrm{N}$ (2015) Methane emissions from natural gas infrastructure and use in the urban region of Boston, Massachusetts. Proc Natl Acad Sci 112(7):1941-1946

Saunois M, Jackson RB, Bousquet P, Poulter B, Canadell JG (2016) The growing role of methane in anthropogenic climate change. Environ Res Lett 11(12):120207

Schaefer H, Fletcher SEM, Veidt C, Lassey KR, Brailsford GW, Bromley TM, Dlugokencky EJ, Michel SE, Miller JB, Levin I, Lowe DC (2016) A 21st-century shift from fossil-fuel to biogenic methane emissions indicated by 13CH4. Science 352(6281):80-84

Sweeney C, Karion A, Wolter S, Newberger T, Guenther D, Higgs JA, Andrews AE, Lang PM, Neff D, Dlugokencky E, Miller JB (2015) Seasonal climatology of $\mathrm{CO}_{2}$ across North America from aircraft measurements in the NOAA/ESRL global greenhouse gas reference network. J Geophys Res Atmospheres 120(10):5155-5190

Sweeney C, Dlugokencky E, Miller CE, Wofsy S, Karion A, Dinardo S, Chang RYW, Miller JB, Bruhwiler L, Crotwell AM, Newberger $\mathrm{T}$ (2016) No significant increase in long-term $\mathrm{CH} 4$ emissions on North Slope of Alaska despite significant increase in air temperature. Geophys Res Lett 43(12):6604-6611

Thompson RL, Stohl A, Zhou LX, Dlugokencky E, Fukuyama Y, Tohjima Y, Kim SY, Lee H, Nisbet EG, Fisher RE, Lowry D (2015) Methane emissions in East Asia for 2000-2011 estimated using an atmospheric Bayesian inversion. J Geophys Res Atmos 120(9):4352-4369

Tian H, Chen G, Lu C, Xu X, Ren W, Zhang B, Banger K, Tao B, Pan S, Liu M, Zhang C (2015) Global methane and nitrous oxide emissions from terrestrial ecosystems due to multiple environmental changes. Ecosyst Health Sustain 1(1):1-20

Tsuboi K, Matsueda H, Sawa Y, Niwa Y, Takahashi M, Takatsuji S, Kawasaki T, Shimosaka T, Watanabe T, Kato K (2016) Scale and stability of methane standard gas in JMA and comparison with MRI standard gas. Pap Meteorol Geophys 66:15-24

Turner AJ, Jacob DJ, Wecht KJ, Maasakkers JD, Lundgren E, Andrews AE, Biraud SC, Boesch H, Bowman KW, Deutscher NM, Dubey MK, Griffith DWT, Hase F, Kuze A, Notholt J, Ohyama H, Parker RJ, Payne VH, Sussmann R, Sweeney C, Velazco VA, Warneke T, Wennberg PO, Wunch D (2015) Estimating global and North American methaneemissions with high spatial resolution using GOSAT satellite data. Atmos Chem Phys 15(12):7049-7069. https ://doi.org/10.5194/acp-15-7049-2015

Wu S, Hu Z, Hu T, Chen J, Yu K, Zou J, Liu S (2018) Annual methane and nitrous oxide emissions from rice paddies and inland fish aquaculture wetlands in southeast China. Atmos Environ 175:135-144

Publisher's Note Springer Nature remains neutral with regard to jurisdictional claims in published maps and institutional affiliations. 